\title{
Nutrient Use Efficiency and Nutrient Uptake Promoting of Rice by Potassium Solubilizing Bacteria (KSB)
}

\author{
M. Yaghoubi Khanghahi ${ }^{1 *}$, H. Pirdashti ${ }^{1}$, H. Rahimian ${ }^{2}$, \\ G.A. Nematzadeh ${ }^{3}$ and M. Ghajar SePanlou ${ }^{4}$ \\ ${ }^{1}$ Department of Agronomy, Genetics and Agricultural Biotechnology Institute of Tabarestan and Sari \\ Agricultural Sciences and Natural Resources University, Sari, Iran \\ ${ }^{2}$ Department of Plant Pathology, Sari Agricultural Sciences and Natural Resources University, Sari, Iran \\ ${ }^{3}$ Department of Plant Breeding, Genetics and Agricultural Biotechnology Institute of Tabarestan and \\ Sari Agricultural Sciences and Natural Resources University, Sari, Iran \\ ${ }^{4}$ Department of Soil Sciences, Sari Agricultural Sciences and Natural Resources University, Sari, Iran
}

(Received 5 March 2018; Accepted 22 May 2018)

The current study was carried out in both pot and field conditions to investigate the effects of three KSB strains of Pantoea agglomerans, Rahnella aquatilis and Pseudomonas orientalis on nitrogen $(\mathrm{N})$, phosphorous $(\mathrm{P})$ and potassium $(\mathrm{K})$ uptake, nutrient use efficiency parameters and nutrients remobilization in rice (Oryza sativa L. cv. Pajohesh). The experiments included 15 treatments of KSB inoculations, commercial $\mathrm{K}$ biofertilizer and $\mathrm{K}$ chemical fertilizer. The results showed that the inoculums of all three KSB strains increased the $\mathrm{K}, \mathrm{N}$ and $\mathrm{P}$ uptake by grain and straw, especially when applied in combination with $1 / 2 \mathrm{~K}$ chemical fertilizer $(47.5 \mathrm{Kg} / \mathrm{ha})$ as compared to the control treatment. The highest value of available K in the soil obtained from NPK chemical fertilizer equal to 140.1 and $134.6 \mathrm{mg}$ $\mathrm{K}$ per $\mathrm{kg}$ of soil in the pot and field experiments, respectively, which were significantly higher than KSB inoculations treatments. Bacterial inoculums coupled with $1 / 2 \mathrm{~K}$ chemical fertilizer also enhanced the nutrient use efficiency (including agronomic efficiency (AE), apparent recovery efficiency (ARE), physiological efficiency (PE), agro-physiological efficiency (APE), internal utilization efficiency (UE), partial factor productivity (PFP), partial nutrient balance (PNB)) and nutrient remobilization. The results indicated that the bioinoculation with these KSB strains isolated from soil paddy could be considered as an effective way to increase potassium, nitrogen and phosphorus uptake by rice plant and enhance their use efficiency and remobilization to grains in the flooding irrigation conditions.

Keywords: nutrient remobilization, nutrient use efficiency, nutrient uptake, potassium solubilizing bacteria

\section{Introduction}

Farmers usually use urea as N, triple super phosphate as $\mathrm{P}$ and potassium sulphate as $\mathrm{K}$ fertilizers for rice production (Bakhshandeh et al. 2015; Yaghoubi Khanghahi et al. 2017). The global average of NPK fertilizers application by farmers is $107 \mathrm{~kg} \mathrm{ha}^{-1}$ (Meena et al.

\footnotetext{
*Corresponding author; E-mail: yaghubis@yahoo.com
} 
2017) and their use efficiency is around $30-60 \%$ for $\mathrm{N}$, less than $20 \%$ for $\mathrm{P}$, and $30-50 \%$ for $\mathrm{K}$ (Fageria 2014). On the other hand, there is a critical level of available $\mathrm{K}$ in 100,000 hectares of paddy field in Iran (Raheb and Heidari 2012). Therefore, farmers apply large amounts of NPK chemical fertilizers, which can results in negative effects on soil and environmental quality and food safety (Bakhshandeh et al. 2017a).

New generation technologies is being applied to improve crops yield and reduce the chemical fertilizers input while minimizing adverse impacts on the environment and food by global agricultural researchers (Pii et al. 2015). For this purpose, the application of plant growth promoting rhizobacteria (PGPR) as bio-fertilizer could be considered in rice cultivation systems, as a potential way to improve fertilizer efficiency and to decrease negative environmental problems (Mishra et al. 2013). The PGPRs such as K-solubiling bacteria (KSB) are root-colonizing bacteria which can grow in, on/or around plant tissues and enhance plant growth (Scagliola et al. 2016; Meena et al. 2017). The KSBs are able to release potassium from insoluble minerals and make them available to the plants (Nath et al. 2017).

Nutrient use efficiency (NUE) usually is defined as the nutrient output or the crop output per unit of nutrient input (Meena et al. 2014; Naeem et al. 2017). It has been reported that PGPR can enhance nutrient bioavailability and promote nutrient acquisition by plants (Pii et al. 2015). PGPR is most frequently studied to determine direct beneficial impacts on plant growth but there is very little information about the effect of KSB inoculations (alone or combined with K-chemical fertilizer) on NUE. Furthermore, the impact of KSB inoculations on nutrients remobilization in rice plants during growth has not been characterized. This research was conducted to investigate the effects of three KSB strains on NPK uptake by plant, NUE parameters and nutrients remobilization in rice plant.

\section{Materials and Methods}

Three KSB strains of Pantoea agglomerans, Rahnella aquatilis and Pseudomonas orientalis were isolated from the paddy rhizosphere soil across Mazandaran province in northern Iran. The soil characteristics, isolation of KSB, their potassium solubilizing ability and identification methods are fully described in Yaghoubi Khanghahi et al. (2017). This research was designed to evaluate their abilities in improving rice yield and nutrient use efficiency. To meet this purpose, the pot and field experiment were conducted in a paddy field of Mazandaran province (Sari, located at $36^{\circ} 3^{\prime} \mathrm{N}, 53^{\circ} 04^{\prime} \mathrm{E}$ ) in a completely randomized design (CRD) and randomized complete block design (RCBD) with three replications, respectively. The three KSB strains were grown in nutrient broth medium (NB, Merck, Germany; $8 \mathrm{gl}^{-1}$ ) as described by Yaghoubi Khanghahi et al. (2017). Rice seedlings (cv. Pajohesh, an improved cultivar) were inoculated with each bacterial suspension at room temperature $\left(\mathrm{RT}, 25^{\circ} \mathrm{C}\right.$ ) for $5 \mathrm{~h}$. Control rice seedlings were also treated in the same way with non-inoculated NB medium before transplanting in the field and pot. In addition, a commercial K bio-fertilizer (formulated by Zist-Phanavar-Sabz Company, Iran) including two isolates of Pseudomonas koreensis and Pseudomonas vancouverensis was tested to compare with the native KS bacteria. 
Pot experiment was performed under optimal agronomic conditions. Three plants were transplanted in each pot with $6 \mathrm{~kg}$ of sterile soil. Experimental soil was collected from rice growing area, where field experiment was conducted. In the field experiment, nine square meter plots $(3 \times 3 \mathrm{~m})$ were arranged and the 25 day old seedlings (about $20-25 \mathrm{~cm}$ in height) were transplanted in the plots at a spacing of $20 \times 20 \mathrm{~cm}$. In order to prevent water penetration through plots, a fixed distance of $100 \mathrm{~cm}$ was determined between plots. The chemical and physical properties of the soil (at a depth of 0-30 cm) were $1.96 \%$ organic carbon; $\mathrm{pH} 7.4$; electrical conductivity of the soil saturation extract (EC) $0.6 \mathrm{dS} \mathrm{m}^{-1} ; 0.17 \%$ total $\mathrm{N} ; 8 \mathrm{mg} \mathrm{kg}{ }^{-1}$ available $\mathrm{P}$ and $94 \mathrm{mg} \mathrm{kg}^{-1}$ available $\mathrm{K}$ and the soil type was clay loam (32\% sand; $38 \%$ silt; $30 \%$ clay). Based on the results of the soil test, urea $(46 \% \mathrm{~N})$ was used as a nitrogen fertilizer equivalent to $160 \mathrm{Kg} \mathrm{ha}^{-1}$. Phosphorous and potassium fertilizers were added through triple super phosphate $\left(46 \% \mathrm{P}_{2} \mathrm{O}_{5}\right)$ and potassium sulphate $\left(44 \% \mathrm{~K}_{2} \mathrm{O}\right)$ equivalent to 120 and $95 \mathrm{Kg} \mathrm{ha}^{-1}$, respectively, as basal fertilizer before transplanting the rice seedlings. Two thirds of the urea fertilizer application was also added during land preparation before planting, while the remaining part (rest) was applied 30 days after transplanting. Plots were weeded by hand. If necessary, appropriate chemical control of pests and diseases were applied. A water depth of three $\mathrm{cm}$ was kept to all pots and plots from transplanting time until two weeks before harvest maturity. The experiment treatments are presented in Table $\mathrm{S}^{*}$.

Rhizospheric soil samples were collected from each pot and plot at harvesting time and were analyzed to determine the exchangeable $\mathrm{K}$ content in soil. Moreover, rice grain and straw were dried and were used to determine of N, P and $\mathrm{K}$ concentration at flowering and harvesting times. Available K was determined by flame photometer (Bakhshandeh et al. 2017a). P concentration and total $\mathrm{N}$ of plant samples was measured by the methods of Bartels and Bigham (1996) and Kjeldahl method, respectively.

The parameters were evaluated (Table S2) such as NPK uptake in grain and straw, nutrient harvest index (NHI, Eq. 1), agronomic efficiency (AE, Eq. 2), physiological efficiency (PE, Eq. 3), agro-physiological efficiency (APE, Eq. 4), apparent recovery efficiency (ARE, Eq. 5), internal utilization efficiency (UE, Eq. 6), partial factor productivity (PFP, Eq. 7), partial nutrient balance (PNB, Eq. 8), nutrient remobilization from flag leaf (NRL, Eq. 9) and nutrient remobilization from stem (NRS, Eq. 10) (Bakhshandeh et al. 2013; Fageria et al. 2011; Fageria et al. 2014; Meena et al. 2017; Naeem et al. 2017).

\section{Results}

\section{Nutrient Uptake by plant}

According to the results of the pot experiment, $\mathrm{K}$ uptake by grain reached the maximum value equal to $2.23 \mathrm{gr} \mathrm{m}^{-2}$ in NPK treatment which was about 3.2, 2.9 and 1.6 times more than the control (-NPK), NP and $\mathrm{NP}^{1} / 2 \mathrm{~K}$ treatments, respectively. Nevertheless, there were no statistically significant differences between NPK treatment and $\mathrm{NP}^{1} / 2 \mathrm{~K}+R a$, $\mathrm{NP}^{1} / 2 \mathrm{~K}+P a+R a$ and $\mathrm{NP}^{1} / 2 \mathrm{~K}+P a+P s$ treatments. $\mathrm{K}$ concentration in straw was higher than

\footnotetext{
*Further details about the Electronic Supplementary Material (ESM) can be found at the end of the article.
} 
that in grain. The maximum significant increases for $\mathrm{K}$ uptake by straw were found in $\mathrm{NP}^{1} / 2 \mathrm{~K}+P a+R a, N P K$ and $\mathrm{NP}^{1} / 2 \mathrm{~K}+R a$ treatments equivalent to $10.81,10.73$ and 10.71 $\mathrm{gr} \mathrm{m}^{-2}$, respectively (Table $\mathrm{S} 3$ ).

Pot experiment results showed that the $\mathrm{N}$ and $\mathrm{P}$ uptake by plant were affected by $\mathrm{K}$ chemical fertilizer application and KSB inoculation. P concentration in grain and straw varied from 0.97 to 1.94 and 0.69 to $1.43 \mathrm{gr} \mathrm{m}^{-2}$, respectively. The highest $\mathrm{P}$ uptake by grain and straw were achieved by $\mathrm{NP}^{1 / 2} \mathrm{~K}+P S$ and $\mathrm{NP}^{1 / 2} \mathrm{~K}+P a+P s$ treatments, respectively. The inoculation with $P$. agglomerans and $P$. orientalis combined with $1 / 2 \mathrm{~K}$ chemical fertilizer significantly increased the amount of $\mathrm{N}$ concentration in grain and straw as compared to treatments without K fertilizer and KSB inoculations (Table S3). Based on pot experiment results, single KSB inoculations non-significantly increased available $\mathrm{K}$ in the soil in comparison with -NPK and NP treatments. The highest value obtained from NPK chemical fertilizer equal to $140.1 \mathrm{mg} \mathrm{K}$ per $\mathrm{kg}$ of soil which was 52.6, 50.1 and $19.9 \%$ more that $-\mathrm{NPK}, \mathrm{NP}$ and NP1/2K treatments (Table S3).

The results of field experiment showed that the $\mathrm{K}$ uptake by grain and straw were significantly influenced by $\mathrm{NP}^{1} / 2 \mathrm{~K}+P a+R a$ treatment which were about $2.7,2.5$ and 1.4 times in grain and 2.5, 2.2 and 1.5 times in straw more than -NPK, NP and NP $1 / 2 \mathrm{~K}$ treatments, respectively. On the other hand, the highest $\mathrm{N}$ uptake by grain and straw belonged to $\mathrm{NP} 1 / 2 \mathrm{~K}+P a+R a$ treatment equivalent to 7.3 and $4.2 \mathrm{gr} \mathrm{m}^{-2}$, respectively. Also, the significant increase of $\mathrm{P}$ concentration in grain and straw were 96 and $108 \%$, when the seedlings were treated by $\mathrm{NP}^{1 / 2} \mathrm{~K}+P S$ and $\mathrm{NP}^{1 / 2} \mathrm{~K}+P a+P S$ treatments as compared to the control, respectively (Table S3). Accordingly, the exchangeable K content in soil was higher when NPK chemical fertilizer was used alone (without KSB inoculations) in the field experiment, which was significantly higher than other treatments. There were no significant differences between KSBs inoculation in terms of releasing K in the soil (Table S3).

\section{K use efficiency}

Different results obtained from pot and field experiments in terms of some $\mathrm{K}$ use efficiency parameters such as KHI, PE, PEP and UE. Accordingly, the highest KHI was belonging to $\mathrm{NP}^{1} / 2 \mathrm{~K}+R a+P S$ treatment which was not statistically significant in the pot experiment. This value was 17.5 and $21.5 \%$ in the pot and field experiments, respectively (Table S4). Statistical analysis of pot experiment showed that the maximum amount of AE, UE, PFP, PNB and ARE were 39.5, 140.6, 296.2, $6.2 \mathrm{gr} \mathrm{gr}^{-1}$ and 388\%, respectively, which was obtained from $\mathrm{NP}^{1 / 2} \mathrm{~K}+R a$ treatment. Although, there was not significant difference between $\mathrm{NP}^{1 / 2} \mathrm{~K}+R a$ and $\mathrm{NP}^{1} / 2 \mathrm{~K}+R a+P S$ treatments. On the other hand, the maximum PE and APE was found when NP+Pa treatment was applied (Table S4).

The results of field experiment indicated that the largest value of AE, UE and PFP was about $69.4,151.1$ and $315.3 \mathrm{gr} \mathrm{gr}^{-1}$, respectively, which was obtained from $\mathrm{NP} 1 / 2 \mathrm{~K}+R a+P S$ treatment. The highest value of PE and APE were $121.4 \mathrm{gr} \mathrm{gr}^{-1}$ and $46.4 \%$ in the $\mathrm{NP}+P S$ treatment. Also, the maximum value of PNB (0.51 $\left.\mathrm{gr} \mathrm{gr}^{-1}\right)$ and ARE (279.4\%) were recorded when $\mathrm{NP}^{1} / 2 \mathrm{~K}$ fertilizer coupled with $P$. agglomerans and $R$. aquatilis inoculations (Table S4). 


\section{$N$ and $P$ use efficiency}

Based on pot experiment results, $\mathrm{N}$ and $\mathrm{P}$ use efficiency were influenced by KSB inoculations alone or combined with K chemical application. However, NPK fertilizer treatment increased some $\mathrm{N}$ use efficiency parameters such as AE, PE, APE and PFP value to about 4.1, 1.7, 3 and 1.2 times more than the NP fertilizer treatment, respectively. Similarly, the highest of these parameters of P use efficiency was obtained from NPK treatment, which was 10.6, 1.4, 2.6 and 1.2 times higher than NP treatment, respectively. The largest value of $\mathrm{N}$ and $\mathrm{P}$ internal utilization efficiency (UE) were recorded equal to 68.2 and $90.9 \mathrm{gr}$ $\mathrm{gr}^{-1}$, respectively, when $\mathrm{NP}^{1 / 2} \mathrm{~K}+R a$ treatment was applied. The maximum of PNB (15.5 $\mathrm{gr} \mathrm{gr}^{-1}$ ) and ARE (55\%) value for $\mathrm{N}$ belonged to $\mathrm{NP}^{1} / 2 \mathrm{~K}+R a+P s$ which no significant differences were found with $\mathrm{NP}+R a$ and $\mathrm{NP}^{1} / 2 \mathrm{~K}+P s$ treatments. $\mathrm{NP}^{1 / 2} \mathrm{~K}+P a+P s$ had a more positive effect on PNB and ARE value for $\mathrm{P}$. The results also showed that the $\mathrm{P}$ and $\mathrm{N}$ harvest index varied from 57.3 to $59.4 \%$ and 62.9 to $66.4 \%$, respectively (Table S5 and S6).

Similar to the pot experiment, the results achieved from field experiment confirmed that the $\mathrm{N}$ and $\mathrm{P}$ use efficiency were affected by applied treatments. $\mathrm{NP} / 2 \mathrm{~K}+R a+P s$ treatment significantly increased some $\mathrm{N}$ use efficiency parameters such as AE, UE, PFP, PNB and ARE values to about 2.7, 3, 1.3, 1.2 and 1.8 times more than the NP fertilizer, respectively. The largest amount of $\mathrm{PE}$ and $\mathrm{APE}$ for $\mathrm{N}$ was obtained from $\mathrm{NP}^{1} / 2 \mathrm{~K}+P a+R a$ and $\mathrm{NP}^{1 / 2} \mathrm{~K}+R a$ treatments, respectively. By contrats, in field, there was a not statistically significant difference between treatments in term of $\mathrm{N}$ and $\mathrm{P}$ harvest index (NHI and PHI). The NHI and PHI values varied from 62.47 to $66.24 \%$ and 57.39 to $59.43 \%$, respectively. The AE, PE, UE and PFP amounts for $\mathrm{P}$ reached the highest values in the $\mathrm{NP}^{1} / 2 \mathrm{~K}+R a+P s$ treatment equivalent to $41,322.7,88.6$ and $119 \mathrm{gr} \mathrm{gr}^{-1}$, respectively, which did not show any significant difference with $\mathrm{NP}^{1} / 2 \mathrm{~K}+R a$ treatment. Similar to the pot experiment, $\mathrm{NP}^{1} \frac{1}{2} \mathrm{~K}+P a+P s$ treatment had a higher effect on PNB and ARE values for $\mathrm{P}$ (Table S5 and S6).

\section{Nutrient remobilization}

In the pot experiment, potassium, nitrogen and phosphorous nutrients presented mobility characteristics which allowed them to be assimilated in the leaves and stems, and then later remobilized to the grain. However, $\mathrm{K}$ remobilization from the stems was differed with $\mathrm{N}$ and $\mathrm{P}$ remobilizations. Accordingly, $\mathrm{K}$ accumulation in the stem at the flowering stage was higher than the harvesting stage. The K remobilization from the leaf (KRL) and stem (KRS) up to $31.7 \%$ and $-13.4 \%$ were recorded in NPK fertilizer treatment. Also, the KRL and KRS were significantly affected by applied K chemical and KSB inoculations as compared to the $-\mathrm{NPK}$ and NP fertilizer treatments. Application of $\mathrm{NP} 1 / 2 \mathrm{~K}+R a+P s$ treatment significantly increased the PRL and PRS with highest value to about $58.6 \%$ and $57 \%$ as compared to the lowest value to around $45.5 \%$ and $42.9 \%$ obtained from -NPK treatment. The increments in the NRL and NRS were recorded by application of NPK chemical fertilizer and KSB inoculations compared to the -NPK treatment. The largest 
values were $58.4 \%$ and $55.6 \%$ achieved by $\mathrm{NP}^{1} / 2 \mathrm{~K}+R a$ and $\mathrm{NP}^{1} / 2 \mathrm{~K}+R a+P S$ treatments, respectively (Table $\mathrm{S} 7$ ).

Based on the field experiment results, the KRL reached the highest percentage $(32.9 \%)$ in the $\mathrm{NP}^{1} / 2 \mathrm{~K}+R a+P s$ treatment which was 1.9 and 1.5 times higher than the $-\mathrm{NPK}$ and NP treatments. The KRS values did not differ between $\mathrm{K}$ chemical fertilizer treatments (applied alone or combined with three KSB inoculations). Similar to pot experiment, the maximum percentage of KRS $(-14.5 \%)$ was obtained from NPK fertilizer. The maximum of $\mathrm{P}$ remobilization from flag leaf and stem were equivalent to $58.6 \%$ and $53.4 \%$, when $\mathrm{NP}^{1} / 2 \mathrm{~K}+P s$ and $\mathrm{NP}^{1} / 2 \mathrm{~K}+R a+P s$ treatments were applied, respectively. Results clearly showed that the $\mathrm{N}$ remobilization from flag leaf and stem were significantly influenced by NPK application alone or coupled to KSB inoculations. The NRL and NRS percentage varied from $43.5 \%$ to $56.7 \%$ and 45.6 to $54.8 \%$, respectively (Table S7).

Regression of quadratic equation models significantly $(\mathrm{P}<0.01)$ fit correlations between available $\mathrm{K}$ in soil at harvest time and $\mathrm{K}$ uptake by grain and stem. These coefficients of determination $\left(\mathrm{R}^{2}\right)$ of the equations were 0.70 and 0.77 in the pot experiment, as well as 0.73 and 0.70 in the field experiment, respectively (Figure S1 and S2).

\section{Discussion}

According to the previous study, . agglomerans, $R$. aquatilis and P. orientalis solubilize 44,88 and $60 \mu \mathrm{g} \mathrm{ml}^{-1}$ of insoluble mica powder as potassium source after 28 days of inoculation, respectively (more details in Yaghoubi Khanghahi et al. 2017). The pot and field experiments were conducted to assess the potential effects of these KSB strains (applied alone or coupled to K chemical fertilizer) to promote nutrient uptake, remobilization and NUE in rice. The results indicated that the KSB inoculations not only increased K uptake by grain and straw, but also enhanced the $\mathrm{N}$ and $\mathrm{P}$ concentrations in the grain and straw, especially when they were applied in combination with $1 / 2 \mathrm{~K}$ chemical fertilizer. These findings are in agreement with Bakhshandeh et al. (2017a, 2017b) and Bahadur et al. (2016) who reported that the mineral nutrient (especially K) uptake by plant increased as influenced by bio-inoculation. In fact, these bacterial strains may be able to solubilize other unavailable mineral nutrients such as $\mathrm{P}$ and to fix nitrogen.

Previous studies have shown that the nutrient uptake by rice plant in response to inoculations with $\mathrm{K}$ solubilizing microorganisms significantly increased through direct manner, through biological $\mathrm{N}$ fixation, solubilizing insoluble phosphate and silicate compounds minerals in the rhizosphere and plant hormone production, and by indirect mechanisms including synthesis of antibiotics, enzymes, fungicidal compounds and competition with detrimental microorganisms (Agrawal et al. 2017).

Among all studied $\mathrm{K}$ solubilizing bacterial strains, $R$. aquatilis had a more positive effect on $\mathrm{K}$ uptake by plant than other strains. The highest uptake of $\mathrm{P}$ and $\mathrm{N}$ by plant obtained from $P$. orientalis inoculation as compared to $R$. aquatilis and P. agglomerans. Some Pseudomonas genera have been already reported not only as a biological nitrogenfixing (Li et al. 2017) but also phosphate solubilizing bacteria (Sharma et al. 2013). 
Based on the results, the commercial K biofertilizer (NP + CB treatment) had no significant effects on $\mathrm{K}$ concentration in the grain and straw, except $\mathrm{K}$ uptake by grain in the field experiment. The uptake of K by plant in the NP + CB treatment was also lower than the native KSBs inoculations treatments. This phenomenon could be explained by a lower adaptation to the plant microenvironment (Tabassum et al. 2017). Probably the nonnative strains which applied as a commercial biofertilizer can not compete with the existing native bacterial community for establishment and persistence in the soil. It has been reported that the native PGPRs isolated from rhizospheric soil may be more useful than others because they are already competent, adapted and dominant in a particular geographical area (Bergottini et al. 2015). Also, the native strains are closely associated with the plant systems biology and are generally preferable for inoculation of crops (Santoro et al. 2015).

Results indicated that the exchangeable K content in the soil increased by KSB inoculations combined with $\mathrm{K}$ chemical fertilizer after the harvest. According to the regression equation, the increase of $\mathrm{K}$ content in the soil treated with $\mathrm{K}$ chemical fertilizer and KSB inoculations probably enhanced the ion uptake by root cells, inducing a high accumulation of $\mathrm{K}$ by the grain and straw (Crusciol et al. 2016). In fact, the availability of $\mathrm{K}$ in the soil has a fundamental role in the $\mathrm{K}$ accumulation in rice (Carmeis Filho et al. 2017). Also, Batten (2002) reported that there was a positive significant correlation between K concentration in rice plant and $\mathrm{K}$ availability in the soil.

On the other hand, the KSB inoculations applied singly did not significantly increase the quantity of available $\mathrm{K}$ in the soil. These findings are not in agreement with Bahadur et al. (2016). The reason may be that the soil samples were collected randomly from nonrhizosphere soils in each pot and plot to estimate of $\mathrm{K}$ availability in soils after harvesting, in the same way that was done to determine of the soil chemical and physical properties before transplanting. That's while, the PGPRs are able to release inorganic nutrients from the organic reserves in the narrow region of soil surrounding and influenced by plant roots as rhizosphere soil (Ahemad and Kibert 2014). Also, Prajapati et al. (2013) reported that the KSBs can synergistically solubilize the K materials from insoluble compounds that can be directly absorbed by plants.

Based on the results, NPK chemical fertilizer treatment showed better results than other treatments on K uptake by grain and straw. This result is confirmed by Bakhshandeh et al. (2017b). Nevertheless, the highest $\mathrm{N}$ and $\mathrm{P}$ uptake achieved by KSB inoculations coupled with $1 / 2 \mathrm{~K}$ fertilizer. Some NUE indexes such as AE, UE, PFP, PNB and ARE for $\mathrm{K}$ nutrient were influenced by application of $\mathrm{K}$ chemical fertilizer in combination with KSB inoculations, especially $R$. aquatilis as compared to $1 / 2 \mathrm{~K}$ fertilizer treatment. Whereas the maximum value of PE and APE was belonging to NP treatment combined with three KSB inoculations (without K fertilizer). These differences may be described based on the difference in their equations. Because the denominator of PE and APE equations is total $\mathrm{K}$ uptake in grain plus straw which was significantly lower in the NP+KSBs treatments than $\mathrm{NP}^{1} / 2 \mathrm{~K}+\mathrm{KSBs}$.

Similarly, the results obtained from the pot and field experiments proved that the $\mathrm{N}$ and $P$ use efficiency were affected by application of NPK fertilizer and $N \mathrm{NP}^{1} / 2 \mathrm{~K}+\mathrm{KSB}$ treat- 
ments. These results are in agreement with Meena et al. (2017) who reported that the PGPMs are able to enhance the NUE and nutrient bioavailability in soil. Duarah et al. (2011) found that application of NPK chemical fertilizers in combination with phosphate solubilizing bacteria increased the NUE of the applied fertilizers and decreased the nutrient runoff or leaching in rice.

There were some differences between pot and field experiments in term of AE, PE, APE, UE, PFP and NHI values for N and P nutrients. Accordingly, the largest amounts of the most NUE indexes in the pot experiment belonged to NPK treatment. On the other hand, the highest values of these indices in the field experiment were achieved by $\mathrm{NP}^{1 / 2} \mathrm{~K}+$ KSBs, especially $\mathrm{NP}^{1} / 2 \mathrm{~K}+R a+P S$ treatment. It seems that soil bacterial activities in the field experiment were higher than pot experiment. The reason for this difference may be the use of sterilized soil in the pots. In addition, the pot experiments usually are performed under environmental conditions which seldom or never occur in the field experiment (Vries 1980) such as negative effect of stagnant flooding condition in the pots on rice growth (Chattopadhyay et al. 2017) and microbial activity (Unger et al. 2009).

According to the results, the three studied KSBs can be used as a viable alternative to increase the $\mathrm{K}$ bioavailability in soil, $\mathrm{K}, \mathrm{N}$ and $\mathrm{P}$ concentration in plant and their use efficiency, especially when $1 / 2 \mathrm{~K}$ chemical was applied. These findings are in agreement with the results of several studies that proved the application of PGPRs in nutrient management strategies aimed at decreasing chemical fertilizer consumption and consequently, promoting environmental-friendly crop production (Maheshwari 2010; Meena et al. 2016). It has already been reported that the application of biofertilizer can reduce the cost of K chemical fertilizers about 50 to $60 \%$ (Chandra et al. 2002), increase the amount of organic matter in the soil (Dębska et al. 2016) and enhance the $\mathrm{K}$ fertilizer efficiency (Bahadur et al. 2014).

Based on our findings, nutrient remobilization significantly varied in different treatments. A large amount of $\mathrm{N}$ and $\mathrm{P}$ imported into the grain occurs at the harvest time. Potassium remobilization was also increased from flag leaves to the grains. These results are in agreement with Bakhshandeh et al. $(2013,2017 b)$ who reported that the higher uptake of $\mathrm{N}, \mathrm{P}$ and $\mathrm{K}$ by the rice can enhance the nutrients accumulation in the grain. It has already been reported that about $15 \%$ of total $\mathrm{K}$ uptake in rice plant will be redistributed to the grain (Fageria et al. 2011). Bakhshandeh et al. (2017b) indicated that grain N concentration increased by $5.1 \%$ with the application of $\mathrm{K}$ chemical fertilizer. However, some studies have shown that the KSB inoculations enhanced the amount of K uptake by plant such as rice (Balasubramaniam and Subramanian 2006) and maize (Abou-el-Seoud and Abdel-Megeed 2012), but we did not find any document that indicates the effect of potassium solubilizing bacteria on $\mathrm{N}, \mathrm{P}$ and $\mathrm{K}$ remobilization of rice in the past.

On the other hand, $\mathrm{K}$ accumulation in the stem at the harvesting time was lower than the flowering time. Therefore, negative values achieved by $\mathrm{K}$ remobilization from stem. This is in agreement with the results of Santos et al. (2017) who reported that the relative $\mathrm{K}$ content in the stem increased from $32 \%$ to $56 \%$ during the assessment period of growth (119 days). Similarly, Chen et al. (2008) investigated the accumulation of N, P and K nutrient in different tissues of rice and reported that the $\mathrm{K}$ accumulation in stem at booting 
and heading stages was higher than maturity stage. This can be described by the increasing contribution to the stem dry mass as compared to other plant tissues (Santos et al. 2017). The nutrient accumulation in the stem may increase due to redistribution of nutrients from older leaves for stem elongation and production of new leaves and structural organs (White 2012).

\section{Conclusion}

In conclusion, the current results indicated that the bio-inoculation with three KSB strains of $P$. agglomerans, $R$. aquatilis and $P$. Orientalis isolated from soil paddy could be considered as an effective way to increase potassium, nitrogen and phosphorus uptake by plant and enhance their use efficiency and remobilization to grains. Therefore, these native KSBs strains, as potential bio-inoculants, can help to minimize use of K chemical fertilizer for rice production in the flooding irrigation conditions.

\section{Acknowledgments}

The authors thank the Genetics and Agricultural Biotechnology Institute of Tabarestan (GABIT) and Sari Agricultural Sciences and Natural Resources University (SANRU), Sari, Iran for providing financial support for this study. We also thank Dr. Esmaeil Bakhshandeh for scientific revisions and Mr. Mohammad Alavi, from microbiology lab of GABIT for technical assistance.

\section{References}

Abou-el-Seoud, I.I., Abdel-Megeed, A. 2012. Impact of rock materials and biofer- tilizations on P and K availability for maize (Zea mayz L.) under calcareous soil conditions. Saudi J. Biol. Sci. 19:55-63.

Agrawal, T., Kotasthane, A.S., Kosharia, A., Kushwah, R., Zaidi, N.W., Singh, U. 2017. Crop-specific plant growth promoting effects of ACCd enzyme and siderophore producing and cynogenic fluorescent Pseudomonas. 3 Biotech. 7:1-11.

Ahemad, M., Kibret, M. 2014. Mechanisms and applications of plant growth promoting rhizobacteria. JKSUS. 26(1):1-20.

Bahadur, I., Meena, V.S., Kumar, S. 2014. Importance and application of potassic biofertilizer in Indian agriculture. Int. Res. J. Boil. 3(12):80-85.

Bahadur, I., Maurya, B.R., Kumar, A., Meena, V.S., Raghuwanshi, R. 2016. Towards the Soil Sustainability and Potassium-Solubilizing Microorganisms. In: Meena, V., Maurya, B., Verma, J., Meena, R. (eds) Potassium Solubilizing Microorganisms for Sustainable Agriculture. Springer, New Delhi.

Bakhshandeh, E., Soltani, A., Zeinali, E., Ghadiryan, R. 2013. Study of dry matter and nitrogen accumulation, remobilization and harvest index in bread and durum wheat cultivars. Electron. J. Crop Prod. 6(1):49-69. (In Persian with English abstract)

Bakhshandeh, E., Rahimian, H., Pirdashti, H., Nematzadeh, G.A. 2015. Evaluation of phosphate-solubilizing bacteria on the growth and grain yield of rice (Oryza sativa L.) cropped in northern Iran. J. Appl. Microbiol. 119:1371-1382.

Bakhshandeh, E., Pirdashti, H., Shahsavarpour Lendeh, K. 2017a. Phosphate and potassium-solubilizing bacteria effect on the growth of rice. Ecol. Eng. 103:164-169. 
Bakhshandeh, E., Pirdashti, H., Gilani, Z. 2017b. Application of mathematical models to describe rice growth and nutrients uptake in the presence of plant growth promoting microorganisms. Appl. Soil. Ecol. https:// doi.org/10.1016/j.apsoil.2017.10.040

Balasubramaniam, P., Subramanian, S. 2006. Assessment of soil test based potassium requirement for low land rice in udic haplustalf under the influence of silicon fertilization, Tamil Nadu Agric., Kumulur, Truchirapalli. pp. 621-712.

Bartels, J.M., Bigham, J.M. 1996. Method of soil analysis. Part 3. Chemical methods. SSSA. Medison, WI. USA.

Batten, G.D. 2002. Relating minerals in rice shoots and grain to soil tests, yield and grain quality. A report for the Rural Industries Research and Development Corporation. RIRDC Publication No 02/101.

Bergottini, V.M., Otegui, M.B., Sosa, A., Zapata, P.D., Mulot, M., Rebord, M., Zopfi, J., Wiss, F., Benrey, B., Junier, P. 2015. Bio-inoculation of yerba mate seedlings (Ilex paraguariensis) with native plant growthpromoting rhizobacteria: a sustainable alternative to improve crop yield. Biol. Fertil. Soils. 51(6):749-755.

Carmeis Filho, A.C.A., Crusciol, C.A.C., Nascente, A.S., Mauad, M., Garcia, R.A. 2017. Influence of potassium levels on root growth and nutrient uptake of upland rice cultivars. Rev. Caatinga. 30(1):32-44.

Chandra, K., Ingle, S.R., Bihari, K. 2002. Biofertilizers and its impact on different crops. National Seminar on Biotechnology: Microbes to Man. March 30-31. School of Life Science, Utkal University, Bhubaneswar, Orissa, India. pp. 18-19.

Chattopadhyay, K., Kuanar, S.R., Ray, A., Sarkar, R.K. 2017. Physiological basis of stagnant flooding tolerance in rice. Rice. Sci. 24:(2): 73-84. doi: 10.1016/j.rsci.2016.08.008

Chen, S., Xia, G., Zhang, G. 2008. Nutrition Accumulation, Remobilization, and Partitioning in Rice on No-Tillage Soil. J. Plant. Nutr. 31(11):2044-2058.

Crusciol, C.A.C., Fernandes, A.M., Carmies Filho, A.C.A., Alvarez, R.C.F. 2016. Macronutrient uptake and removal by upland rice cultivars with different plant architecture. Rev. Bras. Cienc. Solo. 40:e0150115.

Dębska, B., Długosz, J., Piotrowska-Długosz, A., Banach-Szott, M. 2016. The impact of a bio-fertilizer on the soil organic matter status and carbon sequestration results from a field-scale study. J. Soil. Sediment. 16:2335-2345.

Delshadi, S., Ebrahimi, M., Shirmohammadi, E. 2017. Influence of plant-growth-promoting bacteria on germination, growth and nutrients' uptake of Onobrychis sativa L. under drought stress. J. Plant. Interact. 12(1):200-208.

Duarah, I., Deka, M., Saikia, N., Boruah, H.D. 2011. Phosphate solubilizers enhance NPK fertilizer use efficiency in rice and legume cultivation. 3 Biotech. 1:227-238.

Fageria, N.K., Dos Santos, A.B., Coelho, A.M. 2011. Growth, yield and yield components of lowland rice as influenced by ammonium sulphate and urea fertilization. J. Plant. Nutr. 34(3):371-386.

Fageria, N.K., Gheyi, H.R., Carvalho, C.S. 2014. Yield, potassium uptake, and use efficiency in upland rice genotypes. II INOVAGRI International Meeting, 13-16 April, Fortaleza, Brazil. pp. 4515-4520.

Li, H.B., Singh, R.K., Singh, P., Song, Q.Q., Xing, Y.X., Yang, L.T., Li, Y.R. 2017. Genetic Diversity of Nitrogen-Fixing and Plant Growth Promoting Pseudomonas Species Isolated from Sugarcane Rhizosphere. Front. Microbiol. 8:1268.

Maheshwari, D.K. 2010. Plant Growth and Health Promoting Bacteria. Springer Science \& Business Media, Germany.

Meena, V.S., Maurya, B.R., Verma, J.P. 2014. Does a rhizospheric microorganism enhance K availability in agricultural soils? Microbiol. Res. 169:337-347.

Meena, V.S., Maurya, B.R., Verma, J.P., Meena, R.S. 2016. Potassium Solubilizing Microorganisms for Sustainable Agriculture. Springer, India.

Meena, V.S., Meena, S.K., Verma, J.P., Kumar, A., Aeron, A., Mishra, P.K., Bisht, J.K., Pattanayak, A. Navved, M., Dotaniya, M.L. 2017. Plant beneficial rhizospheric microorganism (PBRM) strategies to improve nutrients use efficiency: A review. Ecol. Eng. 107:8-32.

Mishra, D.J., Singh, R., Mishra, U.K., Shahi, S.K. 2013. Role of bio-fertilizer in organic agriculture: a review. Res. J. Recent Sci. 2:39-41.

Naeem, M., Ansari, A.A., Gill, S.S. 2017. Essential Plant Nutrients: Uptake, Use Efficiency, and Management. Springer International Publishing AG Switzerland. 
Nath, D., Maurya, B.R., Meena, V.S. 2017. Documentation of five potassium- and phosphorus-solubilizing bacteria for their $\mathrm{K}$ and P-solubilization ability from various minerals. ISBAB. 10:174-181.

Pii. Y., Mimmo, T., Tomasi, N., Terzano, R., Cesco, S., Crecchio, C. 2015. Microbial interactions in the rhizosphere: beneficial influences of plant growth promoting Rhizobacteria on nutrient acquisition process. A review. Biol. Fertil. Soils. 51:403-415.

Prajapati, K., Sharma, M.C., Modi, H.A. 2013. Growth promoting effect of potassium solubilizing microorganism on OKRA (Abelmoscus Esculantus). Int. J. Environ. Agric. Res. 3(1):181-188.

Raheb, A., Heidari, A. 2012. Effects of clay mineralogy and physico-chemical properties on potassium availability under soil aquic conditions. J. Soil Sci. Plant Nutr. 12(4):747-761.

Santoro, M.V., Cappellari, L.R., Giodano, W., Banchio, E. 2015. Plant growth-promoting effects of native Pseudomonas strains on Mentha piperita (peppermint): an in vitro study. Plant. Biol. 17(6):1218-1226.

Santos, E.F., Macedo, F.G., Zanchim, B.J., Camacho, M.A., Lavres, J. 2017. Macronutrients uptake rate and biomass partitioning during early growth of Jatropha plants. Rev. Ciên. Agron. 48(4):565-575.

Scagliola, M., Pii, Y., Mimmo, T., Cesco, S., Ricciuti, P., Crecchio, C. 2016. Characterization of plant growth promoting traits of bacterial isolates from the rhizosphere of barley (Hordeum vulgare L.) and tomato (Solanum lycopersicon L.) grown under Fe sufficiency and deficiency. Plant. Physiol. Biochem. 107:187196.

Sharma, S.B., Sayyed, R.Z., Trivedi, M.H., Gobi, T.A. 2013. Phosphate solubilizing microbes: sustainable approach for managing phosphorus deficiency in agricultural soils. Springer Plus 2:587.

Tabassum, B., Khan, A., Tariq, M., Ramazan, M., Iqbal Khan, M.S., Shahid, N., Aaliya, K. 2017. Bottlenecks in commercialisation and future prospects of PGPR. Appl. Soil. Ecol. 121:102-117.

Unger, I.M., Kennedy, A.C., Muzika, R.M. 2009. Flooding effects on soil microbial communities. Appl. Soil. Ecol. 42(1):1-8.

Vries, M.P.C. 1980. How reliable are results of pot experiments? Commun. Soil. Sci. Plant. Anal. 11(9):895902.

White, P.J. 2012. Long-distance transport in the xylem and phloem. In: Marschner P, (Ed.) Marschner's mineral nutrition of higher plants. 3rd ed. Berlin: Elsevier. pp. 49-70.

Yaghoubi Khanghahi, M., Pirdashti, H., Rahimian, H., Nematzadeh, G.A., Ghajar Sepanlou, M. 2017. Potassium solubilising bacteria (KSB) isolated from rice paddy soil: from isolation, identification to $\mathrm{K}$ use efficiency. Symbiosis. 77(3):1-11.

\section{Electronic Supplementary Material (ESM)}

Electronic Supplementary Material (ESM) associated with this article can be found at the website of CRC at https://akademiai.com/loi/0806

Electronic Supplementary Table S1. Different levels of fertilizer treatments applied in field experiment

Electronic Supplementary Table S2. Summary of commonly used concepts of harvest index and NUE

Electronic Supplementary Table S3. Nutrient uptake by grain and straw and available K in soil at harvest time as influenced by KSB inoculations and K chemical fertilizer

Electronic Supplementary Table S4. K use efficiency indices as influenced by KSB inoculations and K chemical fertilizer

Electronic Supplementary Table S5. N use efficiency indices as influenced by KSB inoculations and K chemical fertilizer

Electronic Supplementary Table S6. P use efficiency indices as influenced by KSB inoculations and K chemical fertilizer 
Electronic Supplementary Table S7. Nutrient remobilization as influenced by KSB inoculations and K chemical fertilizer

Electronic Supplementary Figure S1. The relationship between available K in soil at harvest time and K uptake by grain and straw in the pot experiment

Electronic Supplementary Figure S2. The relationship between available K in soil at harvest time and K uptake by grain and straw in the field experiment 